Copyright (C) 2005 SAGE Publications London, Thousand Oaks CA and New Delhi

Vol 8(3) 289-311; 1367-5494 DOI: $10.1177 / 1367549405054863$ www.sagepublications.com

\title{
Spike, sex and subtext
}

\section{Intertextual portrayals of the sympathetic vampire on cult television}

Milly Williamson

London Metropolitan University

\begin{abstract}
A BSTRACT The vampire Spike of Buffy the Vampire Slayer is the latest in a long line of ambiguous but sympathetic vampires which have caught the public imagination, stretching back to Polidori's Byronesque vampire, Lord

Ruthven. This article argues that the vampire image that circulates across contemporary vampire fan cultures is one that exceeds any individual depiction of the vampire; the sympathetic vampire operates as a metatext for vampire fans who draw on textual cues to interpret vampires sympathetically, even when the text itself does not. In the case of Buffy the Vampire Slayer, the text overtly encourages a sympathetic subtextual reading of Spike by linking his glamour, sex appeal and rebellion to a hinted-at unseen suffering, which is easily recognized by fans. Fans read Spike's bad-boy pose as symbolic of hidden pathos. Indeed, the text adopts conventions associated with fan fiction in order to encourage and sustain a surrounding fan culture.
\end{abstract}

KEYWORDS Buffy, cult TV, fan culture, intertextuality, metatext, outcast, slash fiction, subtext, sympathetic vampire

The vampire Spike fascinates us because of his polymorphous sexuality, his ambiguity and his emergence as a liminal and pathos-ridden figure. But this is not a new departure for the vampire figure; instead Spike draws on a much longer tradition of the suffering vampire. While much film and literary theory of the vampire has focused on the monolithic evil of Dracula (Astle, 1980; Bentley, 1988[1972]; Jackson, 1981; Jones, 1991[1929]; Richardson, 1991[1959]; Roth, 1988; Twitchell, 1985), there is another tradition which precedes him, in which the vampire is a glamorous outcast, sexual deviant, rebel, rogue and tortured soul. Spike updates several of the conventions associated with the image of the vampire as alluring outsider and, as such, is the latest contribution to the longstanding image of the sympathetic vampire - a creature which always firmly inhabits a contemporary cultural landscape. It is this sympathetic 
and ambiguous vampire (rather than the vampire-as-menace) which has produced enormous fan cultures throughout the 20th and early 21 st century; Spike's character connects to this fan culture implicitly, thereby adding to the 'cult' status of Buffy the Vampire Slayer (BtVS).

This article examines Spike's fictional vampiric ancestry. It assesses what Spike shares with previous sympathetic vampires and it considers the way in which this might resonate with audiences. In addition, the article will consider Spike's character innovations and will locate the way in which his character changes depictions of the sympathetic vampire in the specific context of the television text $B t V S$, as well as the larger context of cult television and fan culture.

\section{Reading Spike intertextually}

Initially, Spike's sympathetic appeal was not overtly depicted, for the role of the sympathetic vampire was already occupied by Angel - a vampire with a soul, searching for redemption, who loves and is loved by Buffy. Angel's brooding manliness is in sharp contrast to Spike's peroxide-punk pugnacity. According to a recent biography of Joss Whedon (the series creator of BtVS), Spike's character was 'killed off in the original scripts' (Havens, 2003: 43). However, the biographer suggests that:

While Joss is famous for killing beloved characters, he equally often saves characters slated for death who display unexpected appeal . . Joss liked what he saw enough to make last-minute changes that saved ... [one] of the show's most popular characters. (Havens, 2003: 43)

Spike's 'unexpected' appeal may have been carefully planned, for as Hammonds (2004: 158) suggests, from the outset Spike 'is almost always given the funniest lines and the coolest clothes and he lives an attractive devil-may-care, after-dark existence'. In either case, Spike's appeal stems from the important signifiers that his character shares with previous sympathetic vampires, which signal his pathos to an audience who knows how to read the signs.

Joss Whedon (cited in Golden and Holder, 1998) is candid about the numerous influences for BtVS, including Tomb of Dracula (Marvel Comics, 1971-9), Near Dark (Kathryn Bigelow, 1987), Blade (Stephen Norrington, 1998) and The Lost Boys (Joel Schumacher, 1987). Whedon comments that Spike's looks are 'a little Billy Idol, a little Kiefer Sutherland in The Lost Boys and every guy in a black coat' (cited in Havens, 2003: 83). This combination of looks was an astute choice on Whedon's part, because Billy Idol was one of the few punks to make it big in the US. Meanwhile, Kiefer Sutherland (who at the time was the epitome of 1980s offbeat cool) plays a vampire gang leader in the film The 
punk with the 1950s image of the biker bad boy. Spike's entrance on BtVS in Season 2 plays up to these images of bad boy cool. The script for this scene (which precedes the opening credits) reads:

[Cut to a small park and playground that night. A classic 1958 Dodge Desoto FireFlite crashes through the 'Welcome to Sunnydale' sign and screeches to a halt. Spike gets out and strolls over to the curb. He takes a deep breath and lights a cigarette.]

Spike: Home, sweet home. ${ }^{1}$

Such an entrance signals Spike's alluring and quick-witted rebel pose. But Spike does not simply signify unruly cool; within vampire fandom, his roguish character also conjures up images of hidden suffering and enforced outsiderdom - in short, pathos.

Early in the series, Spike refers to the most popular sympathetic vampires of the previous two decades - Lestat and Louis from Anne Rice's enormously popular vampire chronicles - with a typical cynical aside. When Angel pretends to be evil in the episode 'School Hard' (2:3), he tells Spike that he fooled Buffy by giving her "the puppy dog "I'm all tortured" act'. Spike responds by asking: 'People still fall for that Anne Rice routine? What a world.' A fannish audience are aware of the intertextual popular culture reference, but are also aware (against the surface dialogue between these two characters and alluding elsewhere) that Angel really is a tortured soul. Furthermore, they are reminded of another vampire fan favourite who, just like Spike, bristles to hide his pain - Lestat, the central sympathetic vampire in Anne Rice's novels (1976, 1985, 1988, 1995, 2000). Here, $B t V S$ is addressing its audience as knowing fans, inviting subtextual play and linking Spike's punk rock image to Lestat's own rock-star moment, which (a fannish audience will recall) was his defence against the pain of inhabiting a self that is neither alive nor dead, good nor evil, a self meaningless in the cold light of day, an existence literally beyond the pale.

Reluctance to kill (or at least a tortured conscience about not being able to resist it) is a key component in vampire fans' sympathy with the vampire. ${ }^{2}$ All of the fans interviewed during the course of this research explained that their favourite vampires are pathos ridden. As one American fan put it:

I like the 'can't help it', you know, 'got into this by accident but soldiers on', you know? That's what attracts me and it seems as long as those conditions are met I can be sympathetic. (Fan C)

Fans who read Spike in this intertextual manner have not been disappointed because as the series has progressed, Spike becomes an overt character of suffering and pathos. As with Louis and Lestat, we come to learn of his jaded experience as a human and his own reluctant vampiric 
transformation ('Fool for Love', 5:7). By Season 5, Spike is a permanent and central character in $B t V S$, but one who is portrayed in terms of extreme marginality. Having been implanted with a chip in the previous season (see the Introduction for a summary of this storyline), Spike is no longer able to act vampirically because he is no longer able to harm humans. Yet he is not human and finds himself an outcast, even among the Scooby Gang ${ }^{3}$ - the only humans who know what he is. While it may be argued that the external form of his restraint calls into question Spike's ability to overcome his 'evil', it does not reduce the pathos of his predicament and hints at the 'ensouled' Spike to be introduced at the end of the following season. In Season 5 Spike also grows to love Buffy, but not only does Buffy not return his love, she actually seems to loathe him. Not good enough to be loved by Buffy and, because of his chip, not bad enough to act vampirically, Spike inhabits an excruciatingly liminal self.

Spike's suffering, his intense love for Buffy and the pathos of his predicament contribute deeply to fans' attachment to him. As one frequent poster to the fan website The Bloody Awful Poets' Society writes:

The very reasons we love this vampire are the very reasons he would feel the need to get a soul. Of Course! . . Spike made the choice to be 'redeemed' long before being given a soul ... A chipped Spike can still be a dangerous Spike. But time and time again he allied himself with the Scoobies when he could have chosen to ally himself with the demon world ... and love is blind. If anyone completely embraces that fact, it is Spike... Spike the demon is full of humanity. (Serina, 2002)

Like other sympathetic vampires before him, Spike cannot hide his suffering behind a sardonic pose; and like the vampire Lestat, nor can he submerge his desire to be redeemed, to be good and to love. He is irresistible to audiences because he is, as Serina puts it, a 'demon full of humanity'. However, this sympathetic and pathos-filled vampire has a very long history, as we shall see.

\section{Spike's sympathetic ancestry}

A number of critics have suggested that (prior to Spike) Anne Rice's vampires were the first overtly sympathetic vampires to be depicted in English fiction (DeKelbe-Rittenhouse, 2002; Gelder, 1994). DeKelbeRittenhouse suggests that it is through Rice's works 'that we have our first truly sympathetic view of the vampire as self-aware creature capable of choosing not to murder innocents' (2002: 149). Yet, even Rice's creations are not the first sympathetic vampires in literature, film or on the small screen to resist their vampiric urges. Television offered an earlier sympathetic vampire, Barnabas Collins of Dark Shadows (1966-71). Dark

292 Shadows was due to go off air because of poor ratings, but once the vampire 
Collins was introduced in 1967, the shows ratings soared and its fortunes turned around. The introduction of the sympathetic vampire simultaneously generated a dedicated and large fan club which persists today. Similarly, Hollywood produced a number of sympathetic vampires, including Bela Lugosi's lonely depiction of Dracula (Tod Browning, 1931). A decade later, Universal produced a second sympathetic version of Dracula in House of Dracula (Erle C. Kenton, 1945) in which the vampire was "portrayed as genuinely longing for release from his vampiric "malady" (Silver and Ursini, 1993[1975]: 90). Republic Pictures also produced a sympathetic vampire picture that year, The Vampire's Ghost (Lesley Selander, 1945) featuring Webb Fallon, a reluctant vampire who helps a young traveller, later to fall in love with the traveller's fiancé - a love which eventually destroys him.

The early 1970s brought us a number of sympathetic black vampire movies - Ganja and Hess (Bill Gunn and Fima Noveck, 1973), Blacula (William Crain, 1972) and Scream Blacula Scream (Bob Kelljan, 1973). The latter two 'blaxploitation' movies introduce us to Prince Marmuwalde, an African prince who, in an effort to halt the slave trade, is vampirized by Dracula in 1780. Dracula kills Mamuwalde's wife and entombs Mamuwalde in a coffin which is unwittingly transported to 1960s America, where the vampire escapes. Blacula finds a new love who is identical to his long-dead wife and after the authorities kill her, the devastated Blacula - in the manner of Varney the Vampire - destroys himself.

Spike is descended from all of these sympathetic vampires, including sharing with them a destructive love for a human female for whom he is willing to die. But, as is the case with the sympathetic vampire more generally, Spike reaches back to ideas about vampirism stemming from the Romantic movement and indeed back to Byron.

\section{The vampire's Byronic roots and the cult of the self}

It was through the figure of Byron that the vampire first became popularized. 'Byronmania' contributed deeply to the association between rebellion and a doomed but glamorous outsiderdom which marked the Romantic idea of vampirism. It is widely acknowledged that Polidori's vampiric Lord Ruthven is both modelled on Byron and is revenge on him. Although he was a figure of notorious repute, Byron was adored by the bourgeois public because he was 'becoming the mysteriously flawed hero about whom he wrote' (Wilson, 2000: 53). Due to Byron's infamy and the deliberate confusion over the authorship of 'The Vampyre' on the part of the publishers who attributed it to Byron, 'the vampire was not just born in the novel', but was, as Twitchell comments, 'given an instant popular audience' (1981: 103). Henry Colburn's The New Monthly Magazine published 'The Vampyre' in 1819 (having recently published Lady Caroline Lamb's novel, Glenarvon (1816), which also contained a thinly 
disguised portrait of Byron), thus exploiting the enormous public interest surrounding his figure. Colburn passed the tale on to five other London publishers, who published it in book form in the months that followed and it was soon translated into French, German, Italian, Swedish and Spanish. Later in the century, James Malcolm Ryder's Varney the Vampire popularized the Byronic image of the suffering vampire to a growing reading public, running to 108 penny instalments before it was finally published as a book in 1847. Thus, from its entry into the novel, the popularized image of the vampire in Europe and the anglo-American world had become fused to Byronic images of glamorous outsiderdom, morose fatalism, sexual deviancy and social and artistic rebellion.

\section{The outcast, the self and the appeal of the sympathetic vampire}

Yet while the image of alluring outsiderdom is, as Nina Auerbach puts it, 'dramatically generational' (1995: 5), the vampire comes to enter the 20th century generally as an anti-hero and one which several disenchanted generations were prepared to embrace specifically 'because of its curse' rather than in spite of it (Carter, 1997: 27; emphasis in original). The fascination in the 19th century with vampiric outsiderdom turns to sympathy and emulation in the 'success'-oriented culture of the 20th century, which of necessity is simultaneously the culture of the outcast. Chris Rojek suggests that the vast majority of us suffer from 'achievement famine' (2001: 49); this is due to the way in which the 'democratic ideal of being recognized as extraordinary, special or unique collides with the bureaucratic tendency to standardize and routinize existence' (2001: 149). Lucien Goldmann made a similar point when he suggested that bourgeois society produces an internal contradiction between individualism as a universal value ... and the important and painful limitations that this society itself brought to the possibilities of the development of the individual' (Goldmann, 1975: 12). The official discourses of European and anglo-American culture have promised the right to personal fulfilment and significance, as well as creating the conditions that ensure that its achievement is unattainable. This paradox produces potentially contradictory experiences for the self in cultures which promise (indeed demand) a personal success which the majority cannot achieve. These paradoxical experiences contributed significantly to the rise of fan cultures. Stephen Duncombe explains how this dilemma is experienced by the underground 'zine' writers in the US who experience themselves as 'losers':

While there isn't much they can do about being losers in a society that rewards interests they don't share and strengths they don't have, they can define the value of being a loser and turn a deficit into an asset. (1997: 20) 
Vampire fans respond to the same conditions by experiencing themselves as outsiders and misfits, which is why the figure of the vampire appeals so much. The vampire raises the pain of outsiderdom and offers an appealing Otherness to inhabit. As one British fan comments:

I don't know, perhaps that's why you identify with vampires - because you feel a bit of a misfit. And let's face it, there's more of a better image associated with vampires than, like, werewolves and witches [laughs]. (Fan D)

The character of Spike draws directly on the image of the vampire as Byronic outcast with the revelation of his own (human) history as a (failed) Romantic poet and, after Season 5, his unrequited love for Buffy. Spike connects to contemporary socially-constructed feelings of inadequacy and Otherness more deeply precisely because of his lack of 'talent', 'acceptance' and 'fame'; he suffers from the experience of marginality and disappointment that is the majority experience. Chris Rojek reminds us that our success-oriented celebrity culture 'creates many more losers than winners' (2001: 15). Similarly, Duncombe points out that America's 'meritocracy' forces people to compete for their place in society and rewards the winners. But he comments that:

Where there are winners there are also losers - and lots of them. The winners are celebrated with power, wealth and media representations. The losers - the majority of Americans - are invisible. (1997: 20)

Increasingly, Spike's story arc comes to symbolize outsiderdom and marginality and progressively he is depicted in a more overtly sympathetic light through his love for Buffy and through his rejection both by her and the Scooby Gang. Spike's outsiderdom resonates deeply with fans. One regular contributor to the fan website All About Spike (www.allaboutspike. com) lucidly echoes the views of many fan postings when she explains this appeal:

As a human, he was incredibly sensitive ... As a vampire, Spike is still 'tainted' by humanity ... Spike is capable of love and selflessness. Spike loves more completely and powerfully than any other character on the show ... Why relate to Spike? Spike is the ultimate outcast. He does not fit in anywhere and is struggling to find his place in the world. (Laura, nd)

This description of Spike and his appeal clearly aligns him with the tradition of the sympathetic vampire from the Byronesque to Lestat; the outsiderdom of the self which cannot or will not conform, but also the 'taint' of humanity, a personal rebellion which hides reluctance and despair. These are the key characteristics that Spike shares with each incarnation of the sympathetic vampire, although he updates them with 
late 20th and early 21st-century 'cool'. In this sense, Spike draws on a meta-textual sympathetic vampire which exceeds any individual depiction of the vampire, but which is connected to the accumulation of evolving characteristics that link rebelliousness to outsiderdom and, ultimately, to suffering. Fannish engagement with this figure stems from the way that its outcast status resonates with experiences of the self in a culture which simultaneously demands from us success and happiness and thwarts its possible achievement. Thus, vampire fandom is less a rebellion against these impositions as it is a means of using the image of rebellion to find a way through this central paradox of our culture.

\section{Spike, the cult TV text and the politics of subtext}

The identification with the outcast is one that $B t V S$ references knowingly. This complicates the cultural politics of fandom, particularly around the issue of subcultural engagements with texts. For example, Joss Whedon constructs himself as an outsider (specifically a fannish outsider), as do the cast and creative team. His co-executive producer David Greenwalt has commented, 'If Joss Whedon had had one good day in high school, we wouldn't be here'. Even the actress who plays Buffy, Sarah Michelle Gellar (improbably) constructs herself as an outsider with the comment, 'Kids were hard on me. I was always excluded from everything because I was different' (both cited in Springer, 1999). The cast and producers reinforce the sense that BtVS speaks directly to the experience of outsiderdom; it is an intertextual theme that informs our understanding of the characters and the actors who play them. The experience of outsiderdom and of being a 'loser' is one that has long been engaged with in fandom (cf. Duncombe, 1997) and one that the cult television text BtVS articulates and depends upon in order to attract the 'in-the-know' audiences upon which cult television relies today.

Cult texts, according to Jancovich and Hunt (2004: 27), are 'not defined by any feature shared by shows themselves, but rather by the way they are appropriated by specific groups' of cult fans. However, BtVS is deliberately constructed to be consumed by fan groups in a fannish or 'cult' manner in other words, fans are invited to immerse themselves in the text and produce subtextual readings from the many textual clues.

Fan scholarship has long considered that the subtext of a TV show is the property of fans (rather than the text itself). Fans are considered to read against the grain of authorized or sanctioned meanings in order to develop meanings for themselves which are often outside of, or in opposition to, the canonical text. Jenkins' (1992) well-known argument that fans 'poach meanings' from texts has influenced fan-scholarship's understanding of the subtext for the last decade (Classen, 1998; Dell, 1998; Harris, 1998; Jenkins et al., 2002). However, in the case of BtVS (and most cult texts) a subtextual reading of the show (particularly of the character Spike) is 
invited specifically by the text itself. Fans are not reading against the canonical text in their development of subtextual narratives because the text invites this kind of engagement. Subtextual readings of cult text such as $B t V S$ are not resistant readings of the text, but in line with the offerings of the text.

Indeed, on at least one occasion (halfway through Season 2), the text calls direct attention to the idea of subtext and to its own subtext. In an amusing exchange about the possibility of vampire allure and the surrounding confusions, Buffy and Giles have the following exchange:

Buffy: Vampires are creeps.

Giles: Yes, that's why one slays them.

Buffy: I mean, people are perfectly happy getting along and then vampires come and they run around and they kill people and they take over your whole house, they start making these stupid little mini pizzas and everyone's like, 'I like your mini pizzas', but I'm telling you, I am. .

Giles: [interrupts] Uh, uh Buffy! I . . I believe the ... subtext here is, is, rapidly becoming, uh uh, text. Are you sure there's nothing you want to share?

Although Buffy is not directly discussing Spike here, the text more than hints at her subtextual attraction for vampires and thus the audience are aware that Giles is not misunderstanding the situation as much as Buffy thinks he is. Comments such as this invite the audience into endless speculation, as well as heavily hinting that the effort put into a subtextual engagement with the show will be worth the effort, for these writers, like the fans, are 'in-the know'.

Gwenllian-Jones argues that the cult television text draws attention to:

[The] deficit between what is (or can be) shown and what the avid audience wants to see, explore, develop and know; storylines and sub-plots extend far beyond the diegesis, events imply unshown possible histories and futures; many possible motivations and responses remain unstated. (2000: 13)

Gwenllian-Jones develops this argument to suggest that these textual strategies are 'knowingly employed' to appeal to a cult audience and its need to be 'imaginatively involved' (2003: 166). BtVS (like other cult TV shows) invites the audience to read it as subtext, particularly around the character of Spike.

$B t V S$ 's cult address, then, is one that not only draws on the interpretative practices of fandom, in terms of subtextual extensions of plots and characters, it also draws on one of the key themes of fan culture: an articulation of the experience of outsiderdom. However, being an outsider in fan culture is not only about being rejected, it is also a rejection of the 
'mainstream', which, as has been argued elsewhere, draws on nonprogressive cultural distinctions which deploys the idea of 'knowingness' to police the boundaries of fandom (see Williamson, 2001, 2005). This article suggests that $B t V S$ has packaged both the experience of rejection and the idea of 'knowingness' in order to appeal to a well-educated, middle-class fan base.

\section{Spike as a metatextual vampire star}

It is significant that by the final Season 7 of $B t V S$, Spike is the most popular character in the series (alongside Buffy), generating one of the largest fan followings and the only significant character to be picked up by $B t V S$ 's spin-off series, Angel. Crucial to the fortunes of Spike are the fans' attachment to his screen character. Sarah Gwenllian-Jones has suggested that unlike Hollywood stars, who have a great deal of visibility in the public domain, television stars tend to receive less promotion than the characters they play: "Characters seem to assume "lives" and "identities" of their own, about which the audience know far more than it does about the actors who play them' (2000: 11). The fandom surrounding cult television texts (Gwenllian-Jones' example is Xena: Warrior Princess) 'gives primacy to character over actor' (2000: 12). For Gwenllian-Jones, '[i]t is Xena, not Lawless, who is the focus of the fans' engagement with the series and who is the main object of their fascination and fantasies' (2000: 12). Similarly, vampire fandom gives primacy to screen vampire characters who seem to fulfil the role of the rebel vampire that hides its suffering. Vampire fandom reads Spike as this vampire, rather than Angel, because of Spike's stark outcast status that has marked him as a creature of pathos to a far greater extent than the hunky, brooding and conventionally tall, dark and handsome Angel, who wears his conscience on his sleeve and thus leaves little to the subtextual imagination. Vampire fandom knows and cares sufficiently about the metatextual sympathetic vampire to recognize it in Spike rather than Angel.

It is important to note that the fandom surrounding $B t V S$ is more diverse than either vampire fandom or Xena fandom (both of which focus on a single fictional being) because of the series' ensemble of actors, each of whom attract fans, as well as the fandom which the creative team attract (particularly Joss Whedon). However, Spike has generated a great deal of fandom and it is one which relies on the series' overt subtextual invitation to read this character (at least initially) against the grain of his formal depiction, the series itself relying on fans' understanding of signs of the metatextual sympathetic vampire.

It will be argued below that when Spike is depicted formally as sympathetic (rather than subtextually) the text moves into new subtextual terrain, by writing its characters through the conventions of fan slash 298 fiction. However, for most of the series, Spike's virtue is misrecognized by 
the other characters, leaving the pleasures of this reading to the "in-theknow' fans.

Gwenllian-Jones suggests that stars are 'vaporous presences, signs far removed from their referents' (2000: 12) and that shows such as Xena abolish "altogether the need for an obvious referent in the form of a "real" person' (2000: 12). This sense that fictional figures, rather than flesh-andblood actors, are what count to many fans, can help to explain fan reactions to Spike. This is not to suggest that the actor, James Marsters, is less 'real' to fans than Spike. Instead, the suggestion is that fannish readings of Spike are not exclusively attached to the overt actions of this 'referent' (i.e. Spike), but rather by what is hinted at through intertextual and metatextual references. Thus, rather than suggesting that James Marsters is exceeded by Spike, Spike is exceeded by the metatextual sympathetic vampire. As an object of cult fandom, Spike becomes meaningful to fans because of the existence of a cross-textual, cross-generational sympathetic vampire which transcends him and through which he can be read. This metatextual vampire has certain star-like qualities that also stretch back to Byron and link to contemporary rock-and-roll rebellion. Elizabeth Wilson has noted that Byron's 'reputation anticipated twentiethcentury forms of fame, glamour and notoriety, his personality generating a legend that became more important than his work, although crucially bound up with it' (2000: 54). Through these associations, the 20th-century vampire has become bohemian and a star-like anti-hero.

The importance of a metatextual reading of the vampire is particularly evident from both the fans' and James Marsters' reaction to the episode 'Seeing Red' (6:19), in which Spike attempts to rape Buffy.4 James Marsters, who (like all television stars) has to negotiate between a press of forces (see Hills and Williams in this issue), crucially intervenes in the possible interpretations of Spike resulting from this unpleasant scene, for he knows that his livelihood is dependent upon Spike retaining a sympathetic appeal to fans. His personal appearances following the rape scene bolstered the fannish interpretation of Spike as a sympathetic character; the sympathy for the screen character had become bound up with the sympathy attained by his off-screen comments. On his website and in appearances, Marsters plays the tortured soul to perfection. In one of numerous interviews in 2003 he comments:

That was the hardest day of my life ... It's something I don't even want to watch ... What you see on that screen is just my terror at having to do that scene ... They show it sometimes and I'm always like, 'Oh, God.' I hope that since Spike has a soul he's not capable anymore of doing anything like that. That's what I really hope. That they won't bring him back in that state of mind ... The writers are fabulous, but when I showed up on set that day I told them: 'Sometimes you guys just don't know what you do. You just do not know what you're asking us.' . . . I'm proud of it artistically, but as a human being I never, 
never, never want to do a scene like that again and I will always refuse because I know what it does to me. (Butler, 2003)

Marsters has not only 'suffered' at the hands of the writers (and this sentiment chimes with many fans; the notion of series writers ruining favoured characters is a feature of fan discourse), he also overtly confuses his own emotions with 'what he hopes' for Spike, thus inviting a simultaneous reading of the two. The antipathy that fans have for writers who 'ruin' favourite characters or write them against type can be seen in the following eloquent discussion from a frequent poster to the website The Bloody Awful Poets' Society, who deems Spike's attempted rape of Buffy to be 'a clumsy dramatic tool':

Ever since I saw the unexpurgated version of the bathroom scene, I've been asking myself why the Mutant Enemy $[\mathrm{ME}]$ team felt the need to subject the audience to this disturbing, jarring, out-of-character scene ... if ME want to hammer home the 'Spike is Evil' message given in all of their Season 6 interviews, then I believe they have failed completely. (Ariana, 2002)

Fans consider favourite characters to have a personality and a dramatic life above and beyond the vicissitudes of screenwriters and often judge the writers, rather than the characters, for unacceptable behaviour. The actors who play these characters have to negotiate a way through these conflicting character interpretations, and Marsters handled his negotiation of the rape scene with aplomb, by identifying with the character rather than the writers.

In discussing the character-as-star, Sara Gwenllian-Jones has suggested that:

An important aspect of Lawless's off-screen role in relation to fans is that she can seem to provide a measure of authenticity to fans' interpretations of Xena by sanctioning them either directly, by explicitly endorsing certain readings of the character, or indirectly, by refraining from contradicting such readings. (2000: 15)

In the case of sustaining a sympathetic reading of Spike, Marsters' intervention was crucial. The sympathetic response from fans to Marsters' emotional disclosure fed directly into their understanding of Spike's vampire screen persona. Sara Gwenllian-Jones has commented in relation to Xena that:

The cult star status of Xena puts Lawless in a curious position in relation to her character and, in particular, in relation to her character's fans. She is not expected to 'be' Xena, but she is frequently expected to function as Xena's earthly representative. (2000: 14) 
We can see this process at work in relation to Marsters' intervention in fannish interpretations of Spike - the implication was that this wasn't really 'Spike', it was the series writers. Here, Marsters can be seen to be acting as Spike's 'earthly representative'.

The fannish meta-interpretation of the vampire as a star figure that exceeds any single depiction of the vampire, produces a 'vampire star': a sympathetic and suffering figure, steeped in images of glamorous renown, imbued with personal rebellion. The 'vampire star' is produced not only through the fans' engagement with a text (subtextual or otherwise), but by their engagement with an metatextual (or intertextual) vampire. This interpretation is bolstered by actors such as Marsters, who play along and act as the 'vampire star's' 'earthly representative' in their dealings with fandom and with the media. If, as Gwenllian-Jones suggests, "[t]he Xenaverse effectively takes stardom to its logical conclusion, abolishing altogether the need for an obvious referent in the form of a "real" person" (2000: 12), then the sympathetic 'vampire star' who resides across a variety of texts across time and through a number of actors, takes this process even further. Our interpretations of Spike rely not only on what Spike does in the text, but also what James Marsters says about what he does, also crucially to a long history of sympathetically constructed vampires who have framed the way in which certain cues of glamour and rebellion can be read as pathos.

\section{Slashing Spike and Buffy}

As Spike's character increasingly becomes overtly depicted in a sympathetic light, the text takes its subtextual offering into new terrain. 'Slash' is the term for erotic fan fiction conventionally between same-sex pairings of (usually heterosexual) screen characters. It is considered to fall outside of the heteronormative matrix that governs how we define acceptable sexual behaviour. For early scholars of fandom, slash fiction represents the most subversive of fan activity and the most resistant form of subtextual reading of texts of popular culture. For example, Camille Bacon-Smith, writing about the science fiction slash community in the early 1990s, suggests regarding women science-fiction fans:

Infringing copyrights, the law they break, is only the mildest part of the subversion fomented ... As their greatest transgression, many of the ladies write about sex in all its permutations. (1992: 6)

Bacon-Smith characterized this form of creative activity as one of 'risk' (1992: 208): risk from personal exposure, risk from facing head-on the question of why life 'hurt[s] so much' (1992: 207). Henry Jenkins, one of the best-known scholars of fandom, likens fans to guerrilla fighters who engage in 'various tactics of popular resistance' (1992: 26). He asserts that fan creativity 
rejects the idea of a definitive version produced, authorized and regulated by some media conglomerate. Instead it [fan fiction] pushes towards a world where all of us can participate in the creation and circulation of cultural myths. (Jenkins, 1998)

Writing specifically about slash from the perspective of slash fans (and quoting extensively from interviews with slash authors about their concerns and enthusiasms), Jenkins and colleagues suggest that:

What many slash fans enjoy is the sense of creating their own culture, of participating in the emergence of a new genre that more perfectly expresses their own social visions and fantasies. (Green et al., 1998: 34)

Like Jenkins, Bacon-Smith argues that the women fans are 'inventing a culture' which offers an 'alternative structure for organizing experience' outside of 'masculine culture' (1992: 292). In addition, John Fiske has argued that fans act against 'official culture' and that participation in fan culture produces forms of productivity that lead to 'empowerment' (1992: 32). However, while it is highly debatable that fandom ever constituted such a radical cultural formation, ${ }^{5}$ it is certainly not the case that this oppositional position characterizes fan relations to the cult television text today. There have been enormous changes in terms of deregulation in the television industry in the US (and to a lesser extent in Europe), which have inaugurated an era of the cult television text and have helped to shape its knowing address to its audience. In particular, the proliferation of new networks resulting from the combined force of the repeal of the financial and syndication rules in the US in 1995 led to the emergence of programmes such as $B t V S$, because network television went through 'a crisis in audience demographics' (Jancovich and Lyons, 2003: 2). Holt suggests that network television had a combined audience share of 90 percent in the 1970s, which then shrank to 57 percent in the 1990s (2003: 16). The result was that networks became less concerned with attracting mass audiences, in favour of 'retaining the most valuable audiences: affluent viewers that advertisers were prepared to pay the highest rates to address' (Jancovich and Lyons, 2003: 3). According to Gwenllian-Jones:

From 1990 onward, a number of television series have been produced and marketed precisely in order to attract particular microcultures and to foster within them not just regular viewers but also a high proportion of fans. (2003: 166)

Cult television texts prior to BtVS, such as Xena: Warrior Princess, have openly encouraged audiences to play with its homoerotic subtext in order to attract large and intense fan audiences (cf. Gwenllian-Jones, 2000). ${ }^{6}$ The slash subtext is overtly encouraged even more in the case of $B t V S$. Joss Whedon posted a message on the BtVS fan discussion board, The Bronze, suggesting that the attraction of the 'Buffyverse' is that: 
It lends itself to polymorphous perverse subtext. It encourages it. I personally find romance in every relationship [with exceptions], I love all the characters, so I say B.Y.O. Subtext! (www.cise.ufl.edu/ hsiao/media/tv/buffy/bronze)

$B t V S$ 's extended plotlines, intertextual and metatextual references, its serial nature and lack of closure, is deliberately intended to produce active fan involvement and this is equally true for slash fiction involvement, as Whedon's comments indicate.

Series producers and cult TV stars alike are well aware of the importance of attracting an involved fan audience. For example, Sarah Michelle Gellar is complimentary and astute about fandom:

I don't think we'd be here if it wasn't for the Net. It was the Internet that really kicked us off, because that's where this loyal fan base could get together and spread the word. (cited in Havens, 2003: 45)

As one of the texts of cult TV, BtVS is written explicitly to attract such a fan following. Rather than resisting the meanings of 'mainstream' culture industries, its fans are being invited by the text to engage in fannish subtextual meaning production, because the text itself is written using many of the conventions of fannish subtexts. This is most marked around the way in which the pairing between Spike and Buffy is handled. Their relationship not only draws on the conventions of slash, it also updates them.

While early scholars of fandom considered slash fiction to be primarily the activity of heterosexual women writing about gay relationships between men, the slash fiction surrounding $B t V S$ has expanded greatly the boundaries of slash. Alongside the conventional male-male parings, there are female-female parings to be found, as well as any number of monsterhuman complications to these parings. On the website All About Spike, slash fiction is situated alongside other (what are considered to be more acceptable) forms of fan fiction and writing. Evidence from the discussion pages of key $B t V S$ websites indicates that the gender and sexual orientation of slash writers includes gay, lesbian, bisexual, transgendered and straight. However, the slash stories between Spike and Buffy on All About Spike outnumber all of the other pairings put together and total more than 500. Thus, many fans seem to be taking their cue from the 'slashability' of this pair explored in the text itself. This is not a straightforward heterosexual pairing, because of the gender mobility of the two characters involved (as discussed above and in Amy-Chinn's article in this issue), but it is one with which the text overtly encourages us to play.

Esther Saxey argues that BtVS is 'slashable', precisely because it is "dedicated to dwelling on those interesting "expectations" aroused in the middle of texts' (2002: 192). But while traditionally, slash has dwelled on "emotions and sexual attraction that are "off-limits"" (2002: 199), Buffy is 
already infused with these elements. Even before the depiction of Spike and Buffy's sexual relationship, the text invited the audience to consider the sexual undercurrent between these two characters and its forbidden nature. For example, in Season 4 (before Spike admits his feelings for Buffy) the screen crackles with the frisson between the two. In 'Who Are You' (4:16), to his delight Spike encounters Buffy in a raucous mood, when she says:

I could ride you at a gallop until your legs buckled and your eyes rolled up. I've got muscles you've never even dreamed of. I could squeeze you until you popped like warm champagne and you'd beg me to hurt you just a little bit more.

This encounter between Spike and Buffy is, as the audience knows, really with another Slayer, Faith, whose body has been switched with Buffy's. Yet the subtextual invitation to read Spike and Buffy as erotically paired is clear and Spike looks forward to just such a 'confrontation'. Even though the audience know that this is not 'really' Buffy, we are encouraged overtly to play with just such an idea. Even earlier in Season 4, Spike and Buffy are cast under a spell that finds them engaged and in love ('Something Blue', 4:9) once again alluding to their potential as an erotic pair. The 'slashability' of Spike and Buffy's relationship is hinted at again early in Season 5. In 'Out of Mind' (5:5) Spike dreams that Buffy kisses him and that they both declare their desire. The forbidden desire that is usually refused in television texts appears in $B t V S$ in dream sequences and under the influence of spells, thus deploying the fantasy elements of the text to promote speculative involvement from the audience about the potential erotic pairing of Spike and Buffy.

Also, the depiction of sex as outside of the control of the pairing is a classic slash convention. Often, fans pair couples erotically either because of an external force, or because one of the pair will be put into danger if the pairing does not take place. Through such an event, the pair then discovers their mutual desire and continues the sexual relationship willingly. This is one of their earliest genres of slash fiction and stems from an early pairing between Kirk and Spock, who are forced to mate when abandoned on a planet at a time when Spock was in a state of Pon Farr $^{7}$ and to avoid sexual relations would be fatal. Kirk must decide whether to have sex with Spock and save his life, or not and see his best friend die. After their first sexual encounter, the pair realise their erotic love for one another and their relationship continues. BtVS extends this slash narrative trajectory across two seasons. In true slash style, the dream and then the spell that Buffy is under takes away the element of choice. However, when Spike later creates the Buffybot (a robotic Buffy to have sex with; 'Intervention', 5:18), the real Buffy pretends to be the robot in 304 order to seduce information from him. But when Spike demonstrates his 
honour, she stops pretending to be the Buffybot and kisses him for real. Finally, what fans have anticipated for most of the season, the subtextual slash, becomes text.

Once the series overtly depicts the 'off-limits' sexual relationship between Spike and Buffy rather than strongly hinting at their 'slashability', the text itself becomes 'slash' in its handling of this pairing, both because of Spike's queerness (and Buffy's) and because of its sadomasochistic nature. The sado-masochistic Spike-Buffy pairing might be seen as an extended 'hurt/comfort' story which scholars of fandom have considered central to slash. Buffy assumes the dominant role, while Spike adopts the traditionally feminized role of being 'in love' with Buffy. In Season 6, Buffy uses Spike as her sexual toy. She regularly abuses him physically, mentally and sexually. She beats him, calls him an 'evil, disgusting thing' and insists on sex even when he says 'no'. In 'Smashed' (6:9), the pair's first sexual encounter occurs when Buffy throws Spike against a wall, unzips his trousers and has sex with him. Again in 'Gone' (6:11), she breaks into his room, throws him against the wall and initiates sex. To liken this to slash may be uncomfortable to some, particularly as slash is normally considered to depict hurt/comfort between a pair of lovers with violence stemming from outside. The injury of one partner and the (sometimes sexual) comforting of the other partner, is seen as an eroticization of female nurturance. Bacon-Smith suggests that women fans write hurt/comfort slash because of the experience of pain, which is 'so pervasive in the lives of women that it [lies] like a wash beneath all of the creative efforts of a community' (1992: 270). She comments that in a typical hurt/comfort story:

One hero will be injured ... while his companion worries about him, empathizes with his pain and finally gives comfort ... Throughout the victim remains powerless, but the story of domination undergoes a transformation: beginning as the product of force - bad, masculine, power - it becomes the reflection for his need for caring - good, feminine power. (1992: 272)

For many scholars writing about fandom, the sado-masochistic sexual encounter is a route to nurturance (Bacon-Smith, 1992; Lamb and Veith, 1986; Russ, 1985). However, in the case of the Spike-Buffy pairing it is the sex itself (with all of its perversity) that provides the comfort. The act of sex (for these two, violent and out of control) is the only possible comfort for 'a pair of lovers whose own problems are too vast for them to find anything but transitory comfort' (Saxey, 2002: 202) and even this is fleeting and physical, leaving psychological and emotional suffering neglected.

Like other contemporary cult TV texts that invite slash readings (such as Xena), BtVS has moved on considerably from the male-male pairings that dominated earlier slash fiction. For Bacon-Smith, one side of the male-male pairing represents the female, while the other represents the 
male. She suggests that women may begin by identifying with the feminized man:

[A]s the story progresses, the woman as comforter holds power, even when represented by a man ... In this fictional transformation we see the transmutation of the sadistic urge into the maternal role of self-sacrifice, while the masochistic position of victim remains ever problematic, both attractive and repellent. (1992: 272)

Yet the Buffy-Spike pairing complicates these gender identifications, because here the abuser is female. However, this is not a simple gender inversion - Buffy as masculine and Spike as feminine - for Spike performs both masculinity and femininity (as does Buffy) (see Amy-Chinn's discussion of Spike's 'queerness' in this issue). Indeed, both characters traverse gender boundaries, Buffy adopts the traditional masculine role of initiating sex, she uses Spike for sex and does not show him love, whereas Spike is the loving partner whose emotional needs are not met. Spike's feminization also calls into question Buffy's heterosexuality because Spike occupies a female position and is in love with a female character - an expression of lesbian desire. Further, Spike is being abused by Buffy, which undermines any systematically progressive reading of this pairing, and moreover, Buffy's self-loathing at her attraction to Spike can be read as self-directed homophobia. After Buffy's first aggressive initiation of sexual intercourse, she comments that 'last night was the most perverse, degrading experience of my life'. Saxey argues that 'Buffy-as-Slayer' often stands in for 'Buffy-as-queer', such that when she 'comes out' to her mother as the Slayer, her mother asks: 'Have you tried not being a vampire slayer?' ('Becoming: Part II', 2:22).

Despite the show's hesitancy regarding the queering of Buffy's sexuality, we can see how the gender relations of traditional slash are both engaged in and disrupted. Whereas Bacon-Smith's women occupied a male role in a homosexual relationship in order to explore heterosexual desire, female Spike fans often occupy a male position in a heterosexual relationship to explore polymorphous sexual desire - the moving back and forth between lesbian desire and heterosexual desire. Meanwhile, Buffy's masculine position vis-à-vis Spike invites male fans to engage in the text's polymorphous sexuality at a safe gender distance, because while Buffy may be symbolically male at times, she is actually female. Carol Clover has suggested that horror texts often provide their male viewers with symbolically male 'final girls' in order that the male audience can 'simultaneously experience forbidden desires and disavow them on the grounds that the visible actor is, after all, a girl' (1992: 18). Through Buffy, then, male viewers can also imagine having sex with Spike. Thus the text invites both sexes to engage in forbidden sexual desire, sliding gender roles and perversity, by writing the text as (in this case - slash) subtext. 
However, while academic scholarship on fandom generally has considered fan engagements with and practices around texts to be resistant, particularly in relation to slash fiction, it has been argued here that fans are not producing resistant readings of texts or oppositional meanings. Instead, they are taking up the textual invitations of the cult TV text and reading with the grain of the offerings of subtext, rather than against them. Cult TV depends on just such an involved audience.

\section{Conclusion}

Spike's fannish appeal is generated simultaneously from the existence of the metatextual sympathetic 'vampire star' through which Spike is read, and $B t V S$ 's cult mode of address, which invites (and depends upon) a 'knowing' 'subtextual' reading of Spike's character. Initially, the series hints at Spike's sympathetic, pathos-ridden existence by drawing on the subcultural reading of the 'cool bad boy' vampire as signifying hidden suffering. Once Spike's empathy-inducing pathos is overtly depicted, the series shifts its subtextual allure onto the sexual relationship between Spike and Buffy. The series uses the conventions of slash fiction stemming from television fan culture in its construction of the sexual relationship between Spike and Buffy, thus continuing to generate the cult status upon which such niche market shows depend. $B t V S$ 's overt appeal to cult fandom's understanding of subtextual meanings indicates that such readings are not 'resistant' or 'poached' from the text, but are openly invited. Thus the early academic characterization of fandom as subversive of mainstream television culture, which was predicated on the idea that subtextual meanings were at odds with the intentions of the television text, has been undermined because of the way in which the cult television text deploys subtextual conventions.

\section{Notes}

1. Scripts available from: http://www.buffy-vs-angel.com/buffy_trans_15shtml.

2. As part of a project on vampire fandom 39 vampire fans were interviewed between 1997 and 2004 (some more than once); I also participated in online vampire fandoms and the offline activities of two vampire clubs. Of those interviewed, 10 were specifically fans of $B t V S$ and 29 were fans of the vampire more generally (although some of these fans became fans of $B t V S$ ) (see Williamson, 2005 for a fuller discussion).

3. This is the name that Buffy and her human helpers give to their 'gang'.

4. It is worth remembering that Lestat actually does rape a woman in The Tale of the Body Thief (Rice, 2000). The rape takes place when Lestat is inhabiting the body of a human who has effected the switch. Lestat's disconnection from his own body and his difficulty in controlling his human one in a variety of ways is considered to 'explain' his actions. 
5. For a fuller critique of this approach to fandom, see Williamson (2005). Jancovich offers a critique of the claims about film fandom in Jancovich et al. (2004).

6. Gwenllian-Jones considers this to be a phenomenon of the 1990s cult television text, but Bacon-Smith (1992) demonstrates that it has been developing since the 1970s. Bacon-Smith suggests that shows such as Starsky and Hutch also encouraged their own slash - hurt/comfort. Bacon-Smith notes that in 33 percent of the episodes of the show, "the press releases mentioned as central to the plot injury or direct threat of death to one of the two heroes, while the other worried or saved him' (1992: 158) and concludes that 'fans drew basic concepts from the screen' (1992: 258).

7. 'Pon Farr' is a Vulcan condition that is a plotline from Star Trek. It is not made up by fans, but fans deployed it as the basis for the pairing between Spock and Kirk.

\section{References}

Ariana (2002) 'The "Seeing Red" Bathroom Scene: Why ME Went There, Gender Relations in the Buffyverse, and the Future of Buffy/Spike', The Bloody Awful Poets' Society, autumn. [Available at: http://bloodyawfulpoet. com/essays/seeingred.html]

Astle, R. (1980) 'Dracula as Totemic Monster: Lacan, Freud, Oedipus and History', Substance 25: 98-105.

Auerbach, N. (1995) Our Vampires, Ourselves. Chicago, IL and London: University of Chicago Press.

Bacon-Smith, C. (1992) Enterprising Women: Television, Fandom and the Creation of Popular Myth. Philadelphia: University of Pennsylvania Press.

Bentley, C. (1988[1972]) 'The Monster in the Bedroom: Sexual Symbolism in Bram Stoker's Dracula', in M. Carter (ed.) Dracula: The Vampire and the Critics, pp. 25-34. Ann Arbor: University of Michigan Press.

Butler, K. (2003) 'James Marsters on Life After Buffy', United Press International, 6 November.

Carter, M. (1997) Dracula: The Vampire and the Critics. Ann Arbor: University of Michigan Press.

Classen, S. (1998) 'Redeeming Values: Retail Coupon and Product Refund Fans', in C. Harris and A. Alexandher (eds) Theorizing Fandom: Fans, Subcultures and Identity, pp. 71-86. Cresskill, NJ: Hampton Press.

Clover, C.J. (1992) Men, Women and Chainsaws: Gender in the Modern Horror Film. Princeton, NJ: Princeton University Press.

DeKelbe-Rittenhouse, D. (2002) 'Sex and the Single Vampire: The Evolution of the Vampire Lothario and its Representation in Buffy', in R. Wilcox and D. Lavery (eds) Fighting the Forces: What's at Stake in Buffy the Vampire Slayer, pp. 143-52. Oxford: Rowman and Littlefield.

Dell, C. (1998) "Look at That Hunk of a Man": Subversive Pleasures, Female 308 Fandom and Professional Wrestling', in C. Harris and A. Alexandher (eds) 
Theorizing Fandom: Fans, Subcultures and Identity, pp. 87-110. Cresskill, NJ: Hampton Press.

Duncombe, S. (1997) Notes from the Underground: Zines and the Politics of Alternative Culture. London and New York: Verso.

Fiske, J. (1992) 'The Cultural Economy of Fandom', in L. Lewis (ed.) The Adoring Audience: Fan Culture and Popular Media, pp. 30-49. London:

Routledge.

Gelder, K. (1994) Reading the Vampire. London: Routledge.

Golden, C. and N. Holder (1998) Buffy the Vampire Slayer: The Watchers Guide, Vol. 1. New York: Pocket Books.

Goldmann, L. (1975) Towards a Sociology of the Novel (trans. A. Sheridan).

London: Tavistock Publications.

Green, S., C. Jenkins and H. Jenkins (1998) 'Normal Female Interest in Men Bonking: Selections from the Terra Nostra Underground and Strange Bedfellows', in C. Harris and A. Alexandher (eds) Theorizing Fandom: Fans, Subcultures and Identity, pp. 9-40. Cresskill, NJ: Hampton Press.

Gwenllian-Jones, S. (2000) 'Starring Lucy Lawless?', Continuum: Journal of Media and Cultural Studies 14(1): 9-22.

Gwenllian-Jones, S. (2003) 'Web Wars: Resistance, Online Fandom and Studio Censorship', in M. Jancovich and J. Lyons (eds) Quality Popular Television, pp. 163-80. London: BFI Publishing.

Hammonds, M. (2004) 'Monsters and Metaphors: Buffy the Vampire Slayer and the Old World', in S. Gwenllian-Jones and R.E. Pearson (eds) Cult Television, pp. 115-46. Minneapolis: University of Minnesota Press.

Harris, C. (1998) 'A Sociology of Television Fandom', in C. Harris and A. Alexandher (eds) Theorizing Fandom: Fans, Subculture and Identity, pp. 41-54. Cresskill, NJ: Hampton Press.

Havens, C. (2003) Joss Whedon: The Genius Behind Buffy. London: Titan Books. Holt, J. (2003) 'Vertical Vision: Deregulation, Industrial Economy and Primetime Design', in M. Jancovich and J. Lyons (eds) Quality Popular Television, pp. 11-31. London: BFI Publishing.

Jackson, R. (1981) Fantasy: The Literature of Subversion. London: Methuen.

Jancovich, M. and N. Hunt (2004) 'The Mainstream, Distinction and Cult TV', in S. Gwenllian-Jones and R.E. Pearson (eds) Cult Television, pp. 27-44.

Minneapolis: University of Minnesota Press.

Jancovich, M. and J. Lyons (eds) (2003) Quality Popular Television. London: BFI Publishing.

Jancovich, M., A. Lazaro-Reboll, J. Stringer and A. Willis (2004) Defining Cult Movies. Manchester: Manchester University Press.

Jenkins, H. (1992) Textual Poachers: Television Fans and Participatory Culture. London: Routledge.

Jenkins, H. (1998) 'The Poachers and the Stormtroopers', transcript of a paper presented at the University of Michigan, Red Rock Eater Digest. [Accessed 21 June 2003: http://www.commons.somewhere.com/articles/1998/

The.Poachers.and.the.Sto] 
Jenkins, H., T. McPherson and J. Shattuc (2002) Hop on Pop: The Politics and Pleasures of Popular Culture. Durham, NC and London: Duke University Press. Jones, E. (1991[1929]) 'On the Vampire', in Christopher Frayling (ed.)

Vampyres, pp. 398-417. London: Faber \& Faber.

Lamb P.F. and D.L. Veith (1986) 'Romantic Myth, Transcendence and Star Trek Magazines', in D. Palumbo (ed.) Erotic Universe - Sexuality and Fantastic Literature. New York: Greenwood Press.

Laura (nd) 'Why Redemption?', All About Spike. [Accessed June 2004: http://www.allaboutspike.com/why.html]

Rice, A. (1976) Interview with the Vampire. New York: Ballentine Books.

Rice, A. (1985) The Vampire Lestat. New York: Ballentine Books.

Rice, A. (1988) Queen of the Damned. New York: Alfred A. Knopf.

Rice, A. (1995) Memnoch the Devil. New York: Alfred A. Knopf.

Rice, A. (2000) The Tale of the Body Thief. New York: Alfred A. Knopf.

Richardson, M. (1991[1959]) 'The Psychoanalysis of Count Dracula', in

C. Frayling (ed.) Vampyres, pp. 418-22. London: Faber \& Faber.

Rojek, C. (2001) Celebrity. London: Reaktion Books.

Roth, P.A. (1988) 'Suddenly Sexual Women in Bram Stoker's Dracula', in

M.L. Carter (ed.) Dracula: The Vampire and the Critics, pp. 57-68. Ann Arbor:

University of Michigan Press.

Russ, J. (1985) Magic Mommas, Trembling Sisters, Puritans and Perverts:

Feminist Essays. New York: Crossing.

Saxey, E. (2002) 'Staking a Claim: The Series and its Slash Fiction', in

R. Kaveny (ed.) Reading the Vampire Slayer: The Unofficial Critical

Companion to Buffy and Angel, pp. 187-210. London: I.B. Tauris.

Serina (2002) 'Of Course Spike Would Get a Soul', The Bloody Awful Poets'

Society, autumn. [Accessed March 2004: http:www.bloodyawfulpoet.com/ essay/Spike_soul.html]

Silver, A. and J. Ursini (1993[1975]) The Vampire Film: From Nosferatu to Bram Stoker's 'Dracula'. New York: Limelight.

Springer, M. (1999) 'High School Hell', in Buffy the Vampire Slayer

3(December): 12-15.

Twitchell, J. (1981) The Living Dead: A Study of the Vampire in Romantic

Literature. Durham, NC: Duke University Press.

Twitchell, J. (1985) Dreadful Pleasures: An Anatomy of Modern Horror. Oxford:

Oxford University Press.

Williamson, M. (2001) 'Women and the Vampire: Texts, Fandom and the

Construction of Identity', PhD thesis, Goldsmiths College, University of

London.

Williamson, M. (2005) The Lure of the Vampire: Gender, Fiction and Fandom from Bram Stoker to Buffy the Vampire Slayer. London: Wallflower Press.

Wilson, E. (2000) Bohemians: The Glamorous Outcasts. London: I.B. Tauris. 


\section{Biographical note}

Milly Williamson is a senior lecturer in media, culture and communications at London Metropolitan University. She is the author of The Lure of the Vampire: Gender, Fiction and Fandom from Bram Stoker to Buffy the Vampire Slayer (Wallflower Press, 2005). She has also published research on fan cultures, vampires and the body, and femininity, the gothic and dress. ADDRESS: London Metropolitan University, Ladbroke House, 62-66 Highbury Grove, London N5 2AD, UK. [email: milly.williamson@londonmet.ac.uk] 